\title{
The Causes of Dormancy and the Changes of Endogenous Hormone Content in Cephalotaxus sinensis Seeds
}

\author{
Qianqian Si, Yan Ma, Dekui Zang* \\ Forestry College, Shandong Agricultural University, Taian, China \\ Email: ${ }^{\star}$ zangdk@sdau.edu.cn
}

How to cite this paper: Si, Q.Q., Ma, Y. and Zang, D.K. (2016) The Causes of Dormancy and the Changes of Endogenous Hormone Content in Cephalotaxus sinensis Seeds. Agricultural Sciences, 7, 834-849. http://dx.doi.org/10.4236/as.2016.712076

Received: September 27, 2016

Accepted: December 19, 2016

Published: December 22, 2016

Copyright $\odot 2016$ by authors and Scientific Research Publishing Inc. This work is licensed under the Creative Commons Attribution International License (CC BY 4.0).

http://creativecommons.org/licenses/by/4.0/

\begin{abstract}
In many wild species, seeds are dormancy at maturity and will not germinate even under favorable environment conditions. Dormancy is a complex trail that is determined by many factors. Some studies have shown that cold stratification and the application of gibberellic acid (GA) can break seed dormancy and promote seed germination. The present study investigated the causes of plant dormancy and the effect of cold stratification and different concentrations of exogenous $\mathrm{GA}_{3}$ in regulating Cephalotaxus sinensis seed germination. Results showed that $C$. Sinensis seeds have good water permeability, which suggested that seed coats were not the main cause that inhibited the seed germination. There were germination inhibitions in all parts of seeds, and the order of inhibitory effect was: testa < endosperm (embryo), which indicated that existence of germination inhibitions was the main reason causing seed dormancy. Endogenous GAs and IAA (indole-3-acetic acid) content increased, while ABA (abscisic acid) content decreased over the experiments. ZR (zeatin riboside) content decreased in the early phase of cold stratification, but rebounded by the end of the experimental period. The changes of endogenous hormone indicated that GA, IAA and ZR played a positive role in seed germination, whereas ABA was associated with seed dormancy. Besides, the relative ratio of GA/ABA, IAA/ABA and ZR/ABA may play a more important role than their absolute level during the seed development.
\end{abstract}

\section{Keywords}

Cephalotaxus sinensis, Dormant Reason, Endogenous Hormone

\section{Introduction}

Some seeds fail to germinate even under favorable environmental conditions [1]. This 
phenomenon is common among many woody plants and the degree of seed dormancy varies both among and within species [2]. The timing of germination is determined to a large extent by the depth of seed dormancy. If there is a wide range of environments under which seeds are capable of germination, the seed dormancy is considered to be shallow [3]. Seed dormancy is controlled by the physiological or structural properties of a seed and external conditions [4]. Dormancy can be caused by husk obstruction, morphological embryo hypoplasia, physiological after-ripping, or by chemical inhibitors in seeds, acting individually or in combination [4] [5] [6].

Husk obstruction induced seeds to be dormant due to its features of mechanical constraint, imperviousity or imporosity. Seeds of five Cantabrian Helianthemums germinate massively after coat scarification, with the notable exception of the endemic $\mathrm{H}$. $t i$ netense, whose germination percentages are generally low [7] [8]. Helianthemum seeds were fully differentiated, but seed coat had difficult in permeability, leading to seed dormancy [9]. Khan [10] also pointed out that the difficulty in water permeability was the main reason of Phaseolus lunatus seeds dormancy.

Embryo dormancy is caused by embryo itself, and seeds will not germinate even stripping of seed coat. Embryo dormancy can be divided into morphological and physiological, acting individually or in combination [11]. In many wild species, fruits fell off naturally after maturing, but the embryo has not yet fully developed. After a period of growth, embryo can be fully developed. Seeds of all four Lonicera species have underdeveloped spatulate embryos that are about 20\% - 40\% fully developed (elongated) when dispersed [12]. Ma [13] indicated that when Acanthopanax senticosus seeds matured, the embryo was in heart-shaped embryo stage, with $2.25 \%$ of embryo rate, incomplete structure, no radicle, embryo differentiation, and also didn't have the ability to germinate. Sometimes, seed embryo has developed completely, but the metabolic activity has reduced and has not enough required material, which leads to poor germination even under suitable environmental conditions [14] [15] [16]. Many researches [17] [18] found that physiological after-ripping was a principal reason which caused the dormancy.

Currently, a large number of studies have shown that the inhibitor is considered one of the most important factors causing seed dormancy. Seed germination inhibitors are often present in the fruit or seed endosperm, seed coat and embryo [19] [20] [21]. Randolph and Cox [22] indicated that inhibitors of seed were mainly existed in seed coat, then seed kernel. Also there are many kinds of inhibiting substances, including organic and inorganic matter, and abscisic acid (ABA) is one of the most important inhibitors. Besides, Phenols, aldehydes, and organic acids, such as Malic acid and Citric acid, are also common inhibitory substances.

Endogenous hormones play an important role in seed dormancy, and they act largely in opposition to each other in regulating germination [23]. ABA and gibberellins (GAs) are considered the main endogenous hormones that control seed dormancy and germination [24] [25]. ABA is associated with physiological processes such as seed embryo development, and it keeps a higher level in dormant seeds [26]. GAs involved in the 
regulation of plant growth and development, including seed germination, stem growth, leaf epidermis, flowering development, flower and fruit maturation and other processes at different stages of development [27]. The antagonistic action of the hormones gibberellins (GA) and $A B A$ in regulating seed dormancy breaking and germination is well established [24] [28] [29] [30]. It has been shown that ABA plays a critical role in seed dormancy maintenance, whereas GAs can break seed dormancy and improve seed germination rate [31] [32]. During dormancy-break, the level of ABA decreases with warm or cold stratification, and levels of GAs increase after cold stratification [33] [34]. Benech-Arnold et al. [35] reported that flucting temperature stimulated germination, attributed to a decrease in $\mathrm{ABA}$ concentration in dormant seeds or embryo sensitivity to ABA [36] [37]. Kochanko et al. [38] indicated that abscisic acid (ABA) involved in the regulation of seed dormancy. Studies [39] have showed that in laminated process, IAA content showed an increasing trend generally, which can accelerate the process of dormancy breaking. However, other studies pointed out that IAA had little effect on seed germination, and too high IAA content even will has negative effect. For example, Li [40] indicated that the dormancy was caused by high concentration of IAA in Pinus koraiensis endosperm. ZR can offset the germination-inhibiting substance, regulating seed development of material and energy metabolism [41]. Additionally, in addition to hormones such as ABA, GAs, IAA and ZR, the balanced relationships between hormones play an important regulatory role in seed dormancy. Cao and Cai [42] pointed out that the ratio of $\mathrm{GA}_{1+3} / \mathrm{ABA}$ and $\mathrm{ZRs} / \mathrm{ABA}$ may play a more important role than their absolute level furing the seed development and embryo after ripening.

A Tertiary relict, Cephalotaxus sinensis is endemic to China [43]. Although it is naturally distributed in subtropical climates along the Yangtze River and its southern region, $C$. sinensis has strong resistance to cold and can survive exposure to winters in the Beijing area [44]. The plant has a wide range of uses. For example, it can be cultivated as an ornamental plant in the garden and it can be trained as a bonsai by trimming and modeling. It also contains a variety of bioactive substances, which gives it has broad application in the fields of medicine, toxicology and phytochemistry [45] [46] [47]. In recent years, with the exhumation and improvement of medicinal and ornamental value, many researchers began to study reproductive technology of Cephalotaxus sinensis [43] [48]. However, seeds in the wild remain dormant until the second or third year after lanting [49] [50]. Therefore, it is important to find methods to break seed dormancy.

In the present study, we aimed to investigate the dormant causes and the role of $\mathrm{ABA}, \mathrm{GAs}$, IAA, ZR and their interaction in regulating $C$. sinensis seed dormancy and germination.

\section{Materials and Methods}

\subsection{Seed Sources}

Seeds were obtained from Funiu Mountain of Henan province, China, on the hillside 
with the altitude of 700 meters. After being collected from adult trees in September 2014 , the seeds were air-dried at room temperature and stored containers at $2^{\circ} \mathrm{C}-5^{\circ} \mathrm{C}$.

\subsection{Water Permeability Test}

100 seeds were collected and evenly divided into two groups randomly. Seeds of one groop were knocked out a crack. After weighting, we put seeds in $25^{\circ} \mathrm{C}$ constant temperature incubator, using deionized water soaking seeds. Took out the seeds every two hours (after 12 hours, took once every 12 hours) and sopped up the water on the surface with blotting paper. Then weighted on electronic scales until the seeds weight no longer changed. There were 3 repeats each group.

Water absorption rate $(\%)=\left(\mathrm{W}_{2}-\mathrm{W}_{1}\right) / \mathrm{W}_{1} \times 100 \%$

$\mathrm{W}_{1}$ : weight before water absorption $(\mathrm{g})$

$\mathrm{W}_{2}$ : weight after water absorption $(\mathrm{g})$

\subsection{Changes of Embryo Length}

The embryo and seed length was measured with a vernier caliper. Each treatment comprised three replicates 30 seeds each, and then calculated the embryo and seed length ratio.

\subsection{Bioassay of Extracts}

Bioassay of extracts were extracted by a modification of the methods of Wang \& Wang [51] Weighed accurately seed testa and endosperm (embryo) $2.5 \mathrm{~g}$ each, grinding with $80 \%$ methanol, then diluted with water to $50 \mathrm{ml}$, and mixed for $48 \mathrm{~h}$ in concussion incubator. The experiment was repeated once. The combined methanol extracts were reduced to aqueous phase at $35^{\circ} \mathrm{C}$, followed by diluted to $0.02,0.04,0.06,0.08,0.10$ $\mathrm{g} \cdot \mathrm{mL}^{-1}$. Seeds were germinated on two layers of Whatman No. 3 filter paper moistened with $5 \mathrm{ml}$ of determination liquid in petri dishes at $25^{\circ} \mathrm{C}$. Germination was recorded after $48 \mathrm{~h}$. Protrusion of the radical through the covering structures was used as the criterion for germination. There were 3 repeats each group.

\subsection{Cold Stratification}

Experiments were conducted in test plots at Shandong Agricultural University. To determine the response of seeds to cold stratification, seeds were soaked for $24 \mathrm{~h}$ with water, and $0,200,400$, or $600 \mathrm{mg} / \mathrm{L}$ of $\mathrm{GA}_{3}$, and then mixed with moistened sand in a ratio of 1:3. The mixture of seeds and sand was buried on the leeward side of plots at a depth of $50 \mathrm{~cm}$ and grown for five months. Moisture levels were monitored to avoid oxygen deprivation, water shortage and mold growth during the period of stratification. Measurements were taken every $15 \mathrm{~d}$.

\subsection{Analysis for Endogenous Hormones}

Endogenous hormone content was measured using an ELISA kit, and the samples were prepared as described by Zeng et al. [52]. Approximately $0.5 \mathrm{~g} \mathrm{FW}$ of seeds was ground 
in an ice bath with $5 \mathrm{ml}$ of $80 \%$ methanol as the extraction medium. The extracts were incubated for $4 \mathrm{~h}$ at $4^{\circ} \mathrm{C}$ and centrifuged at $10,000 \mathrm{r} / \mathrm{min}$, also at $4^{\circ} \mathrm{C}$. The supernatant was passed through a Chromosep C18 column that was prewashed with $10 \mathrm{ml}$ of $100 \%$ methanol and $5 \mathrm{ml}$ of $80 \%$ methanol. The combined supernatant was used to measure the ABA, GA, IAA, and ZR concentrations following the user manual procedures given in the kit.

\section{Results}

\subsection{Water Permeability}

As shown in Figure 1, the moisture content of cracked and crack-free seeds showed the same trend. At the early stage of the process, the moisture content increased in varying degrees. By day 108, the cracked seeds had reached a moisture content of $43.40 \%$, and been in a saturated stage. Similarly, the moisture content was $43.25 \%$ after 120 hours soaking. During the treatment period, the absorption rate of cracked seeds was much higher than that of crack-free seeds. But when they were in a saturated stage, the moisture content of the two kind seeds has little difference. It was turned out that $C$. sinensis seeds have good water permeability, which suggested that seed coats were not the main cause that inhibited the seed germination.

\subsection{Changes of Embryo Length}

The embryo and seed length ratio was positively affected by cold stratification and exogenous hormones $\mathrm{GA}_{3}$ (Figure 2). As the cold stratification duration increased, the length ratio all showed an increasing trend. There was no significant difference in length ratio among seeds treaded with 200,400 and $600 \mathrm{mg} / \mathrm{L} \mathrm{GA}_{3}$. During the low temperature treatment, from day 1 to day 60 , the length ratio increased slowly with the changes from $0.468,0.470,0.470$ to $0.476,0.480$ and 0.476 , respectively. Then it increased rapidly, corresponding to $0.525,0.529$ and 0.529 at the end of lamination. The

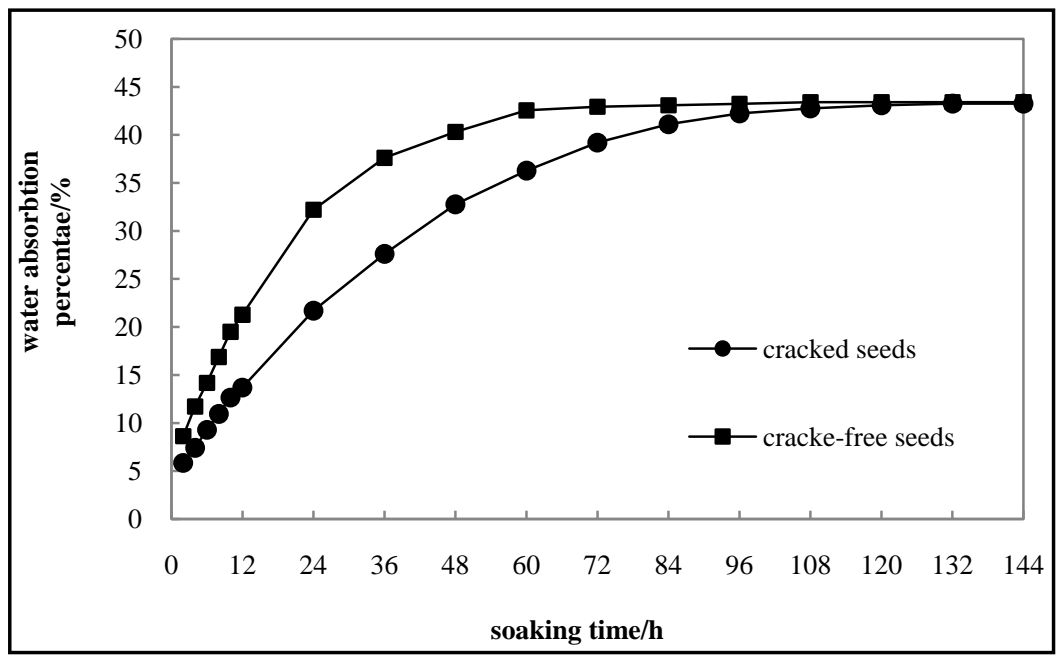

Figure 1. Water uptaking curve of Cephalotaxus sinensis (Rehd. \& Wils.) Li seeds. 


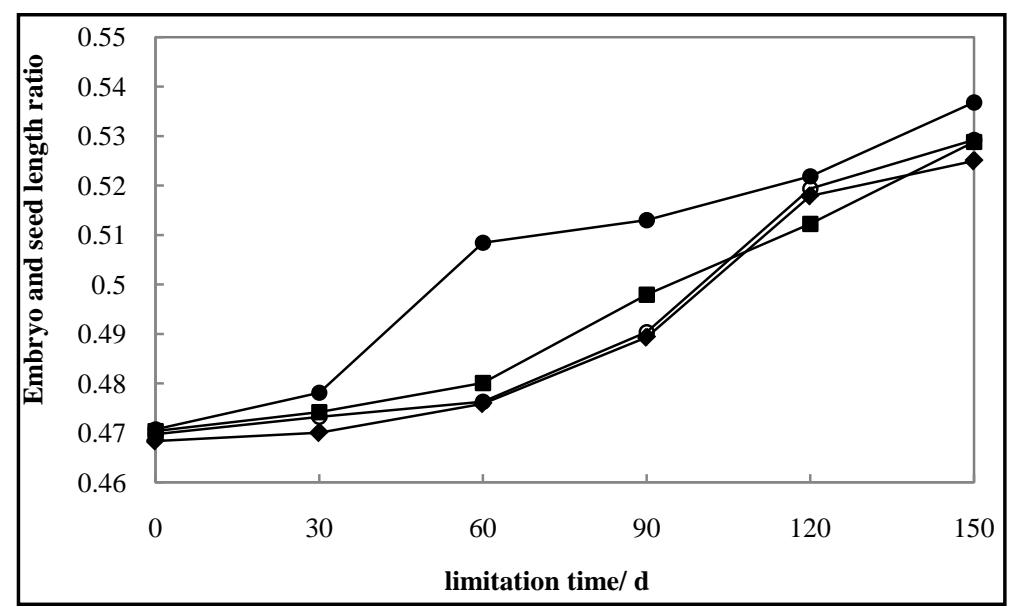

Figure 2. Embryo and seed length ratio of Cephalotaxus sinensis seeds treated with $0(-), 200$ $(-\mathbf{-}), 400(-\mathbf{-}), 600(-) \mathrm{mg} / \mathrm{L}$ of exogenous $\mathrm{GA}_{3}$.

most significant increase in $\mathrm{GA}_{3}$ length ratio was among seeds treated with $200 \mathrm{mg} / \mathrm{L}$ of $\mathrm{GA}_{3}$. At the end of lamination, the ratio reached to 0.537 , much higher than the other three treatments.

\subsection{Bioassay of Extracts}

As shown in Table 1, different concentrations of methanol-extract had extremely significant $(\mathrm{P}<0.01)$ influence on Chinese cabbage seed germination. The results showed that methanol-extract of seed coat and endosperm has different degree of inhibition to Chinese cabbage seed germination. Moreover, the inhibitory intensity and extract concentration was positively correlated. Treated with $0.02 \mathrm{~g} \cdot \mathrm{mL}^{-1}$ of seed coat extract, seed germination was $45.33 \%$, reduced by $50 \%$ compared with the control. However, the seeds treated with $0.02 \mathrm{~g} \cdot \mathrm{mL}^{-1}$ of seed coat extract had a germination rate of $26.67 \%$, reduced by $68.66 \%$ compared with the control. $0.1 \mathrm{~g} \cdot \mathrm{mL}^{-1}$ of seed coat and endosperm extract had the strongest inhibitory effect on seed germination, corresponding to $8 \%$ and $3.33 \%$. It was turned out that seed coat and endosperm both contain germination inhibiting substance, and the order of inhibitory effect was: testa $<$ endosperm.

\subsection{Endogenous Hormones}

Endogenous hormone contents of seeds were affected by cold stratification and application of the exogenous hormone $\mathrm{GA}_{3}$. As a result of cold stratification, the ABA content decreased significantly (Figure 3(a)). In addition, ABA contents in seeds treated with $\mathrm{GA}_{3}$ were much lower compared to the contrast. ABA content in seeds cold stratified for 15 days has little difference among 4 treatments. As the cold treatment duration increased, it had different degree of decrease. At the end of lamination, ABA content was $65.2,31.6,45.2$, and $65.7 \mu \mathrm{g} \cdot \mathrm{g}^{-1}$, decreasing by $46 \%, 74 \%, 64 \%$, and $46 \%$ compared to initial amounts.

Over time, seeds in the cold stratification treatment had generally increased GAs 
Table 1. The effect of methanol-extract of Cephalotaxus sinensis (Rehd. \& Wils.) Li seeds on the germination percentage of $B$. campestris.

\begin{tabular}{cccc}
\hline & & \multicolumn{2}{c}{ Germination percentage of cabbage seeds/\% } \\
\hline Extraction solvent & Concentration $/\left(\mathrm{g} \cdot \mathrm{mL}^{-1}\right)$ & Seed capsule & Endosperm \\
Control & - & $95.33 \pm 0.01 \mathrm{Aa}$ & $95.33 \pm 0.01 \mathrm{Aa}$ \\
& 0.02 & $45.33 \pm 0.13 \mathrm{Bb}$ & $26.67 \pm 0.05 \mathrm{Bb}$ \\
& 0.04 & $38.67 \pm 0.06 \mathrm{Bbc}$ & $14.67 \pm 0.08 \mathrm{Cc}$ \\
Carbinol & 0.06 & $24.67 \pm 0.01 \mathrm{Ccd}$ & $9.33 \pm 0.02 \mathrm{CDcd}$ \\
& 0.08 & $14.00 \pm 0.04 \mathrm{CDde}$ & $4.67 \pm 0.01 \mathrm{Dcd}$ \\
$\mathrm{F}$ & 0.1 & $8.00 \pm 0.05 \mathrm{De}$ & $3.33 \pm 0.03 \mathrm{Dd}$ \\
$\mathrm{P}$ & - & 73.288 & 206.067 \\
\hline
\end{tabular}

content, with some fluctuation. Notably, the most significant increase in GAs content was among seeds treated with $200 \mathrm{mg} / \mathrm{L}$ of $\mathrm{GA}_{3}$ (Figure 3(b)). After 90 days of cold stratification, GAs contents in seeds treated with $200 \mathrm{mg} / \mathrm{L}$ of $\mathrm{GA}_{3}$ were much higher than other three treatments. At the end of lamination, the GAs content reached to 12.2, 9.9 and $10.7 \mu \mathrm{g} \cdot \mathrm{g}^{-1}$, increased by $184 \%, 46 \%$ and $143 \%$, respectively. However, GAs content in seeds treated with $200 \mathrm{mg} / \mathrm{L}$ of $\mathrm{GA}_{3}$ increased to $20.17 \mu \mathrm{g} \cdot \mathrm{g}^{-1}$, with the largest growth by $221 \%$.

Similar to the trend of GAs contents, the trend in IAA content in seeds of all treatments fluctuated over time (Figure 3(d)). IAA content increased from day 15 to day 30, and then decreased until day 75 . The greatest increase was between days 75 and 150, where contents went from $22.3,46.8,29.8$, and $32.6 \mu \mathrm{g} \cdot \mathrm{g}^{-1}$ to $83.0,101.1,64.0$, and 63.6 $\mu \mathrm{g} \cdot \mathrm{g}^{-1}$.

The ZR content decreased first then increased and there were no visible differences among treatments (Figure $3(\mathrm{c})$ ). From day 15 to day 60 , the ZR contents decreased from 9.5, 10.1, 7.5 and $7.5 \mu \mathrm{g} \cdot \mathrm{g}^{-1}$ to $5.6,4.4,3.2$ and $5.1 \mu \mathrm{g} \cdot \mathrm{g}^{-1}$. Then the ZR contents showed an increasing trend.

\subsection{Hormone Ratio}

During cold stratification stress, three was an increasing trend of GAs/ABA ratio in all treatments (Figure 4(a)). In day 90 of stratification, GAs/ABA ratio essentially unchanged, and then it began to rise in different ranges. The ratio had little difference among seeds in the presence of 0,200 and $400 \mathrm{mg} / \mathrm{L}$ of $\mathrm{GA}_{3}$. At the end of lamination, the ratio reached to $0.19,0.22$ and 0.16 , respectively. In the presence of $200 \mathrm{mg} / \mathrm{L}$ of $\mathrm{GA}_{3}$ the GAs/ABA ratio increased rapidly by day 120,135 and 150 , corresponding to $0.18,0.24$ and 0.64 , much higher than other three treatments.

The results of IAA/ABA ratio was shown in Figure $4(\mathrm{~b})$. The ratio of seeds with different treatments showed an increasing trend. The IAA/ABA ratio of seeds treated with $0 \mathrm{mg} / \mathrm{L}$ of $\mathrm{GA}_{3}$ over time fluctuated. During the treatment period from day 15 to day 

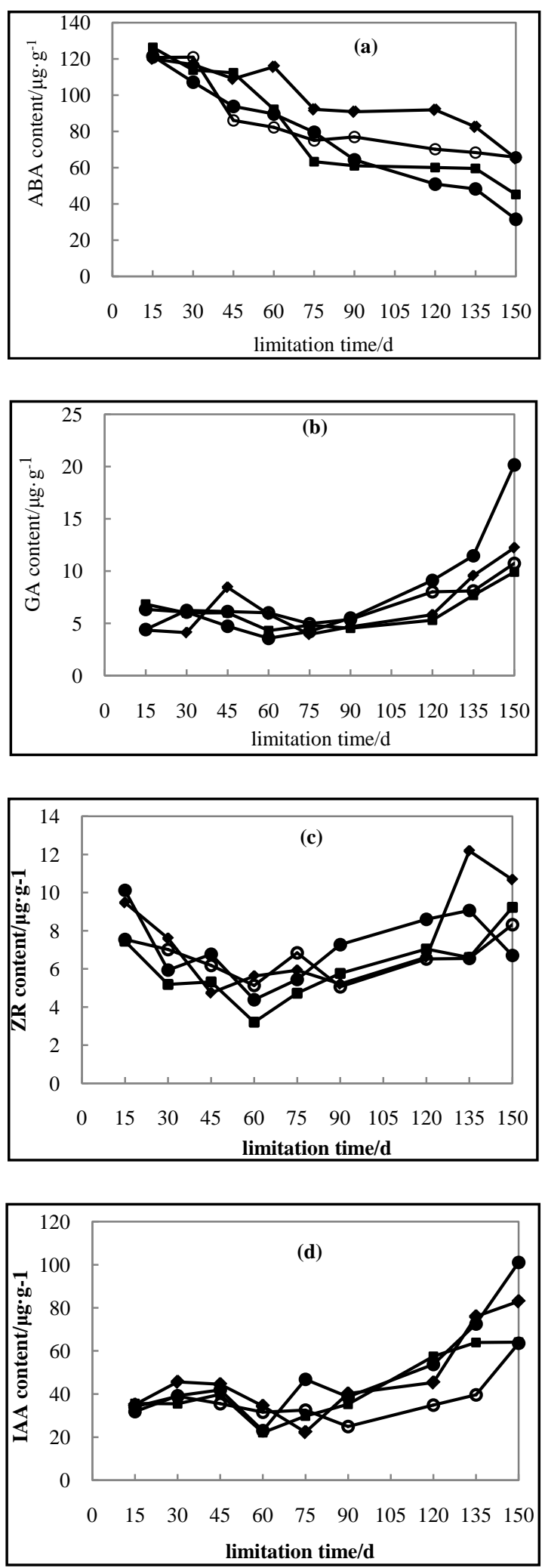

Figure 3. Effects of cold stratification on endogenous hormone ABA (a), GAs (b), ZR (c), IAA (d) contents in Cephalotaxus sinensis seeds treated with $0(-), 200(-)), 400(-)), 600(-)$ $\mathrm{mg} / \mathrm{L}$ of exogenous $\mathrm{GA}_{3}$. 
90 , the ratio of seeds in the presence of 400 and $600 \mathrm{mg} / \mathrm{L}$ of $\mathrm{GA}_{3}$ changed slowly. And then it showed a steady upward trend.

After stratified for 60 days, the ratio of seeds in the presence of $200 \mathrm{mg} / \mathrm{L}$ of $\mathrm{GA}_{3}$ increased rapidly, and after 120 days, the ratio was significantly higher than the other three treatments.

Similarly to the trend of IAA/ABA ratio, the ZR/ABA ratio in seeds of all treatments also showed an increasing trend (Figure $4(\mathrm{c})$ ). After stratified for 60 days, the ratio of seeds with different treatments varied. During the treatment period from day 90 to day 150 , the ratio of seeds in the presence of $200 \mathrm{mg} / \mathrm{L}$ of $\mathrm{GA}_{3}$ changed rapidly and it was significantly higher than other treatments. However, the ratio of seeds treated with 600 $\mathrm{mg} / \mathrm{L}$ of $\mathrm{GA}_{3}$ over time fluctuated, and the ratio increase was the least among seeds
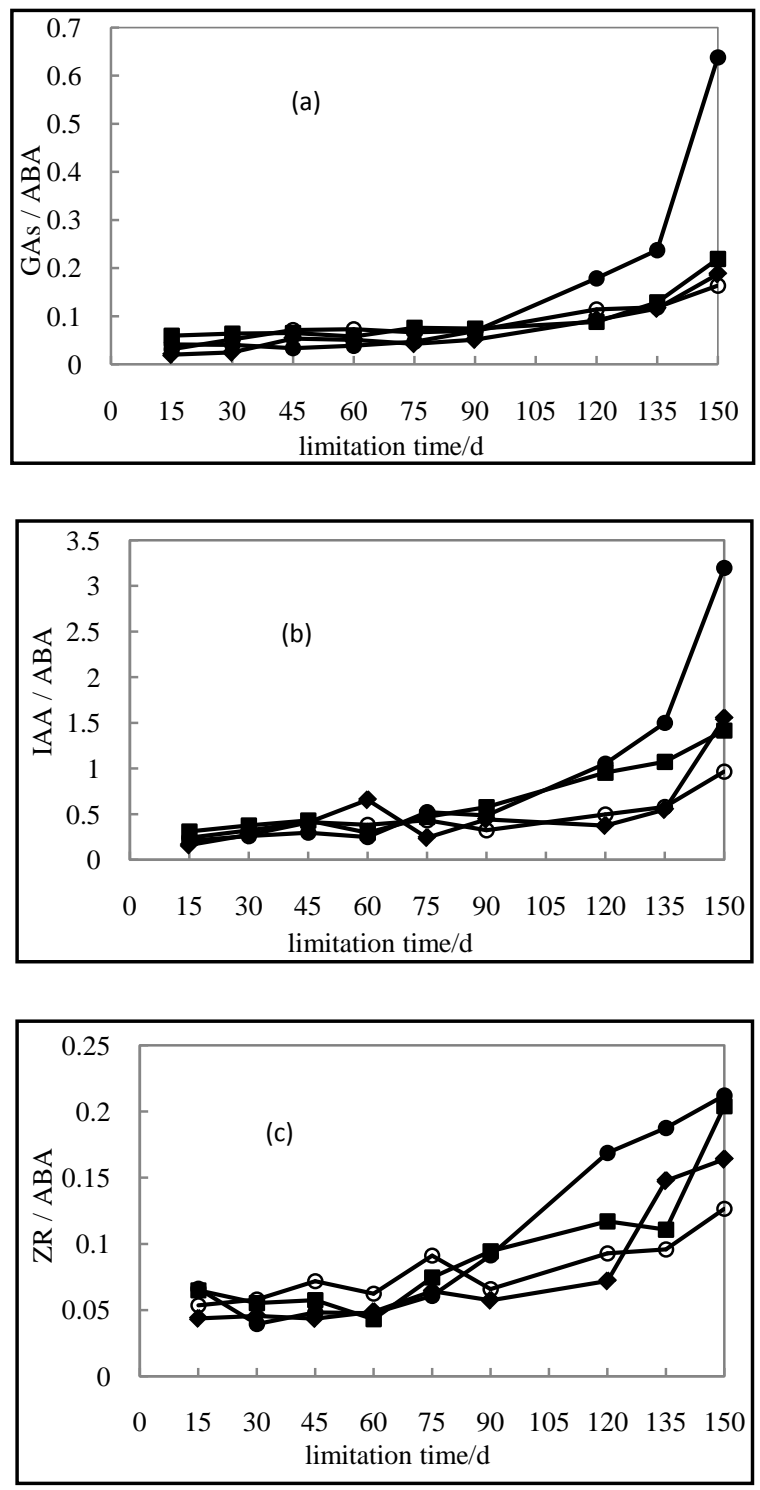

Figure 4. Effects of cold stratification on GAs/ABA, IAA/ABA, ZR/ABA ratio in Cephalotaxus sinensis seeds treated with $0(\bullet), 200(-), 400(\rightarrow-), 600(-)$ mg/L of exogenous $\mathrm{GA}_{3}$. 
with different treatments.

\section{Discussion}

Moisture is a necessary condition of seed germination. It can accelerate the enzyme activity, enhanced respiration and promote the material transformation and transport. Seeds will germinate only under well-watered conditions after mature [53]. Different plant species show a variety of seed structures [54], but as a general rule in angiosperms, the embryo surrounding tissues or seed envelopes prevent germination by providing a physical barrier for the elongating radical [55]. For example, some seeds have compact structure, developed palisade tissue or thick cuticle [56] [57], which will lead to seed dormancy. Various studies have shown that poor water permeability of seed coat is one of the causes of seed dormancy [58] [59]. Results of the present study showed that when they were in a saturated stage, the moisture content of the two kind seeds has little difference. It can reach saturation soaked in water for 5 days, which can be negligible compared with it for 2 - 3 years of inactivity.

As early as in 1956, Asakawa [60] found that seed dormancy related to the incomplete development embryo closely. Physiological dormancy is most common and can be separated into deep and non-deep, of which the latter is the most prevalent and also the major form of dormancy in plant model species [61]. Embryos excised from seeds with non-deep physiological dormancy produce normal seedlings [32]. In the present study, as the cold stratification duration increased, the length ratio all showed an increasing trend. It turned out that the incomplete development embryo may be one of the main causes of seed dormancy.

Inhibiting substance commonly found in dormant seeds, is an important factor leading to seed dormancy [62]. The existence of inhibiting substances hinders certain aspects of seed physiological activities, and further affects seed germination process. The inhibiting substances were present in many plants, such as Paris polyphylla [63] and Acer griseum [64]. Results of the present study showed that the germination of seeds in the presence of extract was much lower compared to controlled experiments. Seed coat and endosperm both contain germination inhibiting substance, and the order of inhibitory effect was: testa < endosperm. And with the increase of extract concentration, the inhibition enhanced. It turned out that the presence of endogenous inhibitors was a major cause of seed dormancy. This is consistent with Sun et al. [65] who showed that inhibiting seed germination substances are contained in the exotesta, inner seed coat and endosperm of Torreya seeds.

The effects of cold stratification on endogenous hormones have been investigated in many studies [35] [66]. ABA and GA are considered the main endogenous hormones that control seed dormancy and germination [24] [25]. ABA is one of the most important inhibitors involved in induction and maintenance of seed dormancy, whereas GA can break seed dormancy and improve seed germination rate [25] [67] [68]. In our cold stratification treatments, ABA content decreased significantly while GA content fluctuated in the early stage of lamination then increased rapidly, paralleling the increase in 
seed germinating ability. Our results suggest that ABA biosynthesis during cold stratification may indeed play a critical role in maintaining seed dormancy, and that GA may be directly associated with seed dormancy breaking and germination. Because ABA and GA are antagonistic to each other, the inhibition of $\mathrm{ABA}$ can stimulate production of $\mathrm{GA}$, and this may be one of the decisive factors for breaking dormancy. This is consistent with a study by Ye et al. [69] that showed that endogenous ABA and GA played an important regulatory role in dormancy and germination. Kochankov et al. [38] and Yang et al. [39] indicated that IAA participated in the regulation of seed dormancy and was also beneficial to breaking seed dormancy. Consistent with this, results of the present study showed that when seeds started to germinate, the IAA in $C$. sinensis seeds increased significantly. Increased levels of ZR can offset germination inhibition and regulate production of substances and affect energy metabolism in seed development [70]. Gao [71] indicated that ZR played an important regulating role in seed dormancy breaking and germination. However, in our study, this was not supported as ZR content decreased first then showed only a slow increase that peaked at day 135 .

Control of seed dormancy may depend on the endogenous balance of biosynthesis and catabolism and thus on the ratio rather than amounts of these plant growth regulators [72]. Studies have pointed out that the ratio of GA and ABA was a key factor in controlling seed dormancy, cold stratification made ratio of GA and ABA increased to relieve seed dormancy [73]. In our study, the $C$. sinensis seeds dormancy was broken and seeds germination increased. This appears to be attributed to inhibition of $A B A$ biosynthesis and an increase of GAs biosynthesis and GAs/ABA ratio. Besides, the relative ratio of IAA/ABA and $\mathrm{ZR} / \mathrm{ABA}$ may play a more important role than their absolute level during the seed development and embryo after-ripening. As can be seen in the hormone content and ratio changes, the dormancy of $C$. sinensis seeds is jointly regulated by a variety of hormones, and increasing ratio of promoting hormones and trophic hormone can effectively break seed dormancy and promote germination.

\section{Conclusion}

The results showed that the presence of endogenous inhibitors and incomplete development embryo were the main causes of seed dormancy. The seed germination rate was related to changes of endogenous ABA, GAs, IAA and ZR. We also observed a change in the ratio of $\mathrm{ABA}$ inhibitors to GA stimulators, which may be a key factor in the breaking of seed dormancy.

\section{Acknowledgements}

This study was supported by the Shandong agricultural seeds engineering major issue (Lunong [2010] No. 6) and National Natural Science Foundation (30972406), and the Advantages Discipline of Colleges and Universities in the Shandong province.

\section{References}

[1] Nasreen, S., Yousaf, M., Mohmand, A.S. and Mailk, M.A. (2012) Study of Seed Dormancy 
Mechanisms; Causes and Control. Asian Journal of Plant Sciences, 1, 210-212.

[2] Olmez, Z., Temel, F., Gokturk, A. and Yahyaoglu, Z. (2007) Effects of Sulphuric Acid and Cold Stratification Pretreatments on Germination of Pomegranate (Punica granatum L.) Seeds. Asian Journal of Plant Sciences, 6, 427-430.

https://doi.org/10.3923/ajps.2007.427.430

[3] Yang, Q.H., Ye, W.H., Song, S.Q. and Yin, S.H. (2003) Summarization on Cause of Seed Dormancy and Dormancy Polymorphism. Acta Botanica Boreali-Occidentalia Sinica, 23, 837-843.

[4] Pawlowski, T.A. (2009) Proteome Analysis of Norway Maple (Acer platanoides L.) Seeds Dormancy Breaking and Germination: Influence of Abscisic and Gibberellic Acids. BMC Plant Biology, 9, 1-13.

[5] Black, M., Bewley, J.D. and Halmer, P. (2008) The Encyclopedia of Seeds: Science, Technology and Uses. CAB International, Wallingford.

[6] Koornneef, M., Bentsink, L. and Hilhorst, H. (2002) Seed Dormancy and Germination. Current Opinion in Plant Biology, 5, 33-36.

https://doi.org/10.1016/S1369-5266(01)00219-9

[7] Carlón, L. (1998) Distribución geográfica y comportamiento ecológico de Helianthemum tinetense Mayor López \& Fernández Benito, endemismoastur-galaico. Bol. Ciencias Nat. RIDEA, 45, 1-12.

[8] López González, G. (1993) Helianthemum Mill. In: Castroviejo, S., Aedo, C., Cirujano, S., Laínz, M., Montserrat, P., Morales, R., Mûnoz Garmendia, F., Navarro, C., Paiva, J. and Soriano, C., Eds., Flora Iberica 3, Real Jardín Botánico-CSIC, Madrid, 365-421.

[9] Perez-Garca, F. (2006) Seed Germination of Five Helianthemum Species: Effect of Temperature and Presowing Treatments. Journal of Arid Environments, 65, 688-693.

https://doi.org/10.1016/j.jaridenv.2005.10.008

[10] Khan, A.A. (1977) The Physiology and Biochemistry of Seed Dormancy and Germination. North Horth Holland Publishing Company, Amsterdam, 1-75.

[11] Hilhorst, H.W.M. (1995) A Critical Update on Seed Dormancy. I. Primary Dormancy. Seed Science Research, 5, 61-73. https://doi.org/10.1017/S0960258500002634

[12] Hidayati, S.N., Baskin, J.M. and Baskin, C.C. (2000) Dormancy-Breaking and Germination Requirements of Seeds of Four Lonicera Species (Caprifoliaceae) with Underdeveloped Spatulate Embryos. Seed Science Research, 10, 459-469.

[13] Ma, S. (2006) Study on the Dormancy Mechanism of Acanthopanax senticosus Seeds. Jilin Agricultural University, Jilin.

[14] Finch-Savagel, W.E. and Leubner-Metzger, G. (2006) Seed Dormancy and the Control of Germination. New Phytologist, 171, 501-523. https://doi.org/10.1111/j.1469-8137.2006.01787.x

[15] Baskin, J.M. and Baskin, C.C. (2008) Some Considerations for Adoption of Nikolaeva's Formula System into Seed Dormancy Classification. Seed Science Research, 18, 131-137. https://doi.org/10.1017/S096025850803674X

[16] Benech-Arnold, R.L.M. and Giallorenzic, F.J. (1999) Termination of Hull-Imposed Dormancy in Developing Barley Grains Is Correlated with Changes in Embryonic ABA Levels and Sensitivity. Seed Science Research, 9, 39-47. https://doi.org/10.1017/S0960258599000045

[17] Zhang, L.P., Chen, Z. and Li, X.N. (1999) Seed Germination Characteristics and Embryo Development of Schisandra chinensis (Turcz.) Bail. Journal of Chinese Material Medica, 24, 
459-461.

[18] Zhang, X.W., Cao, J.J., Gong, Y.X. and Zhang, X.P. (2007) Seed Dormancy and Germination in Rare Plant Pteroceltis tatarinowii Maxim. Journal of Biology, 24, 28-31.

[19] Arditti, J. and Pray, T.R. (1969) Dormancy Factors in Iris (Iridaceae) Seeds. American Journal of Botany, 56, 254-259. https://doi.org/10.2307/2440847

[20] Yagihashi, T., Hayashida, M. and Miyamoto, T. (1998) Effects of Bird Ingestion on Seed Germination of Sorbus commixta. Oecologia, 114, 209-212.

[21] Paulsen, T.R. and Hogstedt, G. (2002) Passage through Bird Guts Increases Germination Rate and Seedling Growth in Sorbus aucuparia. Functional Ecology, 16, 608-616. https://doi.org/10.1046/j.1365-2435.2002.00668.x

[22] Randolph, L.F. and Cox, L.G. (1943) Factors Influencing the Germination of Iris Seed and the Relation of Inhibiting Substances to Embryo Dormancy. Proceedings of the American Society for Horticultural Science, 43, 284-300.

[23] Khan, A.A. (1975) Primary, Preventive and Permissive Role of Hormones in Plant Systems. The Botanical Review, 41, 391-420. https://doi.org/10.1007/BF02860831

[24] Kucera, B., Cohn, M.A. and Leubner-Metzger, G. (2005) Plant Hormone Interaction during Seed Dormancy Release and Germination. Seed Science Research, 15, 281-307. https://doi.org/10.1079/SSR2005218

[25] Hu, X.W., Huang, X.H. and Wang, Y.R. (2012) Hormonal and Temperature Regulation of Seed Dormancy and Germination in Leymus chinensis. Plant Growth Regulation, 67, 199207. https://doi.org/10.1007/s10725-012-9677-3

[26] Abdallah, A., Debez, A., Barhoumi, Z., Smaoui, A. and Abdelly, C. (2009) ABA, GA, and Nitrate May Control Seed Germination of Crithmum maritimum (Apiaceae) under Saline Conditions. Comptes Rendus Biologies, 332, 704-710. https://doi.org/10.1016/j.crvi.2009.03.009

[27] Bewley, J.D. (1997) Seed Germination and Dormancy. Plant Cell, 9, 1055-1066. https://doi.org/10.1105/tpc.9.7.1055

[28] Steffens, B., Wang, J. and Sauter, M. (2006) Interactions between Ethylene, Gibberellin and Abscisic Acid Regulate Emergence and Growth Rate of Adventitious Roots in Deepwater Rice. Planta, 223, 604-612. https://doi.org/10.1007/s00425-005-0111-1

[29] Le Page-Degivry, M.T., Bianco, J., Barthe, P. and Garello, G. (1996) Change in Hormone Sensitivity in Relation to Onset and Breaking of Sunflower Embryo Dormancy. In: Lang, G.A., Ed., Plant Dormancy. Physiology, Biochemistry and Molecular Biology, CAB International, Wallingford, 221-231.

[30] Grappin, P., Bouinot, D., Sotta, B., Miginiac, E. and Jullien, M. (2000) Control of Seed Dormancy in Nicotiana plumbaginifolia: Post-Imbibition Abscisic Acid Synthesis Imposes Dormancy Maintenance. Planta, 210, 279-285. https://doi.org/10.1007/PL00008135

[31] Christmann, A., Moes, D., Himmelbach, A., Yang, Y., Tang, Y. and Grill, E. (2006) Integration of Abscisic Acid Signaling into Plant Responses. Plant Biology, 8, 314-325. https://doi.org/10.1055/s-2006-924120

[32] Baskin, J.M. and Baskin, C.C. (2004) A Classification System for Seed Dormancy. Seed Science Research, 14, 1-16. https://doi.org/10.1079/SSR2003150

[33] Chen, S.Y., Chen, C.T., Baskin, J.M. and Baskin, C.C. (2010) Storage Behavior and Changes in Concentrations of Abscisic Acid and Gibberellins during Dormancy Break and Germination in Seeds of Phellodendron amurense var. wilsonii (Rutaceae). Tree Physiology, 30, 275-281. https://doi.org/10.1093/treephys/tpp111 
[34] Lewak, S. (2011) Metabolic Control of Embryonic Dormancy in Apple Seed: Seven Decades of Research. Acta Physiologiae Plantarum, 33, 1-24. https://doi.org/10.1007/s11738-010-0524-8

[35] Benech-Arnold, R.L., Steinbach, H.S., Kristof, G. and Sa'nchez, R.A. (1995) Fluctuating Temperatures Have Different Effects on Embryonic Sensitivity to ABA in Sorghum Varieties with Contrasting Pre-Harvest Susceptibility. Journal of Experimental Botany, 46, 711717. https://doi.org/10.1093/jxb/46.6.711

[36] Chien, C.T., Kuo-Huang, L.L. and Lin, T.P. (1998) Changes in Ultrastructure and Abscisic Acid Level, and Response to Applied Gibberellins in Taxus mairei Seeds Treated with Warm and Cold Stratification. Annals of Botany, 81, 41-47. https://doi.org/10.1006/anbo.1997.0542

[37] Singh, Z. and Browning, G. (1991) The Role of ABA in the Control of Apple Seed Dormancy Reappraised by Combined Gas Chromatography Mass Spectrometry. Journal of EXperimental Botany, 42, 269-275. https://doi.org/10.1093/jxb/42.2.269

[38] Kochanko, V.G., Gitzesik, M., Chojnowsk, M., et al. (1998) Effect of Temperature, Growth Regulators and Other Chemicals on Echinacea purpurea (L.) Moench Seed Germination and Seedling Survival. Seed Science and Technology, 26, 547-554.

[39] Yang, W.X. and Fang, S.Z. (2008) Dynamic Changes of Endogenous Hormones in Cyclocarya paliurus Seed during Stratification. Journal of Nanjing Forestry University (Natural Sciences Edition), 35, 85-88.

[40] Li, K.J., Jin, Y.J., Chen, H.J., et al. (1997) Changes of Endogenous GAs and IAA Contents in Pinus koraiensis Seeds during Cold Stratification and Germination. Hebei Journal of Forestry and Orchard Research, 12, 203-208.

[41] Wang, S.G. (1999) Cytokinins and Plant Seed Development and Germination. Seed, 105, 35-37.

[42] Cao, B.H. and Cai, C.J. (2006) Study on the After-Ripening Physiology and Endogenous Hormones of Ginkgo biloba Seeds. Scientia Silvae Sinicae, 42, 32-37.

[43] Liu, X.J., Wang, D., Yu, D.L. and Liang, P. (2013) Introduction Performance and Breeding Technology of Cephalotaxus sinensis in Xiongyue Area. Northern Horticulture, 8, 85-87.

[44] Zhou, X.J., Hu, Z.B., Huang, L.D. and Zhang, G.Y. (1997) Studies on Cephalotaxus Plants Resources over China. Journal of Hubei Agricultural College, 17, 100-103.

[45] Bocar, M., Jossang, A. and Bodo, B. (2003) New Alkaloids from Cephalotaxus fortunei. Journal of Natural Products, 66, 152-154. https://doi.org/10.1021/np0203178

[46] Muhammad, K.S., Deng, Y.L. and Dai, R.J. (2008) Attenuation of Biochemical Parameters in Streptozotocin-Induced Diabetic Rats by Oral Administration of Extracts and Fractions of Cephalotaxus sinensis. Journal of Clinical Biochemistry and Nutrition, 42, 21-28.

[47] Hao, S.H., Wei, Y., Zhang, J. and Zhang, X. (2006) Herbicidal Activity of Twig and Needle Extracts from Cephalotaxus sinensis against Amaranthus retroflexus. Chinese Journal of Pesticide Science, 8, 91-94.

[48] Shi, H., An, S.P., Yang, W., Feng, X.Q., Wang, M.Q. and Zhang, J.T. (2007) Study on Cutting and Breeding Trials of Cephalotaxus chinensis. Journal of Gansu Forestry Science and Technology, 32, 23-25.

[49] Chen, H.Y., Zhang, Z.Q. and Chen, F.H. (1964) Flora Hainanca. Science Press, Beijing, 219.

[50] Pang, X.H. and Song, J.Y. (2010) Research Progress of Resources in Cephalotaxus Mannii. Shanxi Journal of Agricultural Sciences, 1, 119-121.

[51] Wang, X.P. and Wang, J.L. (1998) Extraction, Separation and Biological Measurement of 
Endogenous Growth Regulating Substance of Seeds of Pinus bungeana. Seeds, 5, 19-23.

[52] Zeng, Q.Q., Chen, H.B., Lu, C.H. and Li, J.G. (2006) An Optimized HPLC Procedure for Analyzing Endogenous Hormones in Different Organs of Litchi. Journal of Fruit Science, 23, 145-148.

[53] Yan, S., et al. (2014) Optimization of Seed Germination and Detection of Germination Inhibitors in Gardenia Fruits. Journal of Southern Agriculture, 45, 376-382.

[54] Linkies, A., Graeber, K., Knight, C. and Leubner-Metzger, G. (2010) The Evolution of Seeds. New Phytologist, 186, 817-831. https://doi.org/10.1111/j.1469-8137.2010.03249.x

[55] Debeaujon, I., Léon-Kloosterziel, K.M. and Koornneef. M. (2000) Influence of the Testa on Seed Dormancy, Germination, and Longevity in Arabidopsis. Plant Physiology, 122, 403413. https://doi.org/10.1104/pp.122.2.403

[56] Greipsson, S. (2001) Effects of Stratification and GA3 on Seed Germination of a Sand Stabilizing Grass Leymus arenarius Used in Reclamation. Seed Science \& Technology, 29, 1-10.

[57] Yang, W.X., Fu, X.X. and Fang, S.Z. (2005) The Seed Coat Structure of Cyclocarya paliurys and Its Effects on Water Permeability. Journal of Nanjing Forestry University (Natural Sciences Edition), 29, 25-28.

[58] Zhang, F.J., Xu, X.Y., Meng, X.D., Wang, F.B. and Jin, Y.J. (2004) Breaking the Seed Dormancy and Stimulating the Seed Germination of Gleditsia sinensis. Journal of Fujian College of Forestry, 24, 175-178.

[59] Chen, J.L. (1994) A Study on the Seed Dormancy of Euonymus carnosus and Its Commutation. Forest Research, 7, 227-229.

[60] Asakawa, S. (1956) Studies on the Delayed Germination of Fraxinus mandshurica var. Japonica Seeds. Bulletin of the Government Forest Experiment Station, 87, 75-84.

[61] Graeber, K., Nakabayashi, K., Miatton, E., Leubner-Metzger, G. and Soppe, W.J.J. (2012) Molecular Mechanisms of Seed Dormancy. Plant, Cell and Environment, 35, 1769-1786. https://doi.org/10.1111/j.1365-3040.2012.02542.x

[62] Evenari, M. (1949) Germination Inhibitors. The Botanical Review, 15, 153-194.

[63] Chen, S.Y., et al. (2015) Effects of Moist Cold Stratification on Germination, Plant Growth Regulators, Metabolites and Embryo Ultrastructure in Seeds of Acer morrisonense (Sapindaceae). Plant Physiology and Biochemistry, 94, 165-173. https://doi.org/10.1016/j.plaphy.2015.06.004

[64] Zhang, C.H., Zheng, Y.Q., Wu, J., Chen, P. and Li, B.J. (2012) Mechanisms of Seed Dormancy of Acer griseum. Bulletin of Botanical Research, 32, 573-577.

[65] Sun, N., Chen, L., Liu, X.J. and Xing, L. (2016) The Effects of Germination Inhibitors Contained in Torreya grandis Seeds on Seed Germination. Journal of Huangshan University, 18, 44-47.

[66] Huarte, H.R. and Benech-Arnold, R.L. (2010) Hormonal Nature of Seed Responses to Fluctuating Temperatures in Cynara cardunculus (L.). Seed Science Research, 20, 39-45. https://doi.org/10.1017/S0960258509990249

[67] Leubner-Metzger, G. (2003) Functions and Regulation of $\beta$-1,3-Glucanase during Seed Germination, Dormancy Release and After-Ripening. Seed Science Research, 13, 17-34. https://doi.org/10.1079/SSR2002121

[68] Nambara, E. and Marion, P.A. (2010) ABA Action and Interactions in Seeds. Trends in Plant Science, 8, 213-217. https://doi.org/10.1016/S1360-1385(03)00060-8

[69] Ye, Y.H., Zhang, W.X., Zhang, S.W., Huang, H.L. and Ma, Y.X. (2014) The Effects of Cold Stratification on Dormancy Breaking and Endogenous Hormones Changes in Seeds of $\mathrm{Si}_{-}$ 
nopodophyllum hexandrum. Li Shizhen Medicine and Material Medica Research, 25, 715717.

[70] Wu, J., Li, Y.G., Luo, X.B., Tang, Y.Q., Zhou, Y. and Liu, X.H. (2013) Dynamic Changes of Endogenous Hormones in Styrax tonkinensis Seed during the Treatment Process. Acta Agriculturae Universitatis Jiangxiensis, 35, 988-992.

[71] Gao, C.H. (2016) Effects of Exogenous GA on the Endogenous Hormones Content of Acanthopanax senticosus Harms in Ripening. Seeds, 35, 35-37.

[72] Chen, W., Yang, Y., Ma, S.B. and Li, J. (2015) Study on Dormancy Type of Paris polyphylla var. yunnanensis Seeds. Southwest China Journal of Agricultural Sciences, 28, 783-786.

[73] Zhao, X., Ma, X.J., Kaisar, Su, L.M. and Shi, J. (2006) Rule of Breaking Ferula fukanensis Seed Dormancy under Low-Temperature and Content Changes of Endogenous Hormone. Chinese Traditional and Herbal Drugs, 37, 268-270.

\section{Submit or recommend next manuscript to SCIRP and we will provide best service} for you:

Accepting pre-submission inquiries through Email, Facebook, LinkedIn, Twitter, etc.

A wide selection of journals (inclusive of 9 subjects, more than 200 journals)

Providing 24-hour high-quality service

User-friendly online submission system

Fair and swift peer-review system

Efficient typesetting and proofreading procedure

Display of the result of downloads and visits, as well as the number of cited articles

Maximum dissemination of your research work

Submit your manuscript at: http://papersubmission.scirp.org/

Or contact as@scirp.org 